\title{
Information content of female copulation calls in wild long-tailed macaques (Macaca fascicularis)
}

\author{
Antje Engelhardt • Julia Fischer • Christof Neumann • \\ Jan-Boje Pfeifer • Michael Heistermann
}

Received: 26 May 2010 /Revised: 8 November 2010 /Accepted: 5 September 2011 / Published online: 27 September 2011

(C) The Author(s) 2011. This article is published with open access at Springerlink.com

\begin{abstract}
Primates are unusual in that many females display sexual signals, such as sex skin swellings/colorations and copulation calls, without any sex role reversal. The adaptive function of these signals remains largely unclear, although it has been suggested that they provide males with information on female reproductive status. For sex skin swellings, there is increasing evidence that they represent a graded signal indicating the probability of ovulation. Data on the functional significance of copulation calls are much scarcer. To clarify the information content of such calls, we recorded copulation calls in wild long-tailed macaques (Macaca fascicularis) and analysed the structure of these calls during the ovarian cycle. Specifically, we correlated selected call parameters with the female oestrogen to progestogen ratio (obtained from faecal samples), which are known to be elevated during the
\end{abstract}

Communicated by J. Setchell

A. Engelhardt $(\bowtie) \cdot$ C. Neumann $\cdot$ J.-B. Pfeifer

Jr. Research Group of Primate Sexual Selection,

Reproductive Biology Unit, German Primate Center,

Kellnerweg 4,

37077 Göttingen, Germany

e-mail: aengelhardt@dpz.eu

A. Engelhardt

Human Biology and Anthropology, Freie Universität Berlin,

Albrecht-Thaer-Weg 6,

14195 Berlin, Germany

J. Fischer

Research Group Cognitive Ethology, German Primate Center,

Kellnerweg 4,

37077 Göttingen, Germany

\section{Heistermann}

Reproductive Biology Unit, German Primate Center,

Kellnerweg 4,

37077 Göttingen, Germany female's fertile phase. In addition, we ran a general linear mixed model for these call parameters, testing factors (cycle phase, occurrence/absence of ejaculation, male dominance status, occurrence/absence of mate guarding) which potentially influence female copulation calls in primates. Our results show that copulation calls of female long-tailed macaques signal mating outcome and rank of the mating partner, but not female reproductive status. They also show for the first time on primates that copulation calls can convey information on whether a female is mate guarded or not. We suspect that the function of these calls is manipulation of male mating and mate-guarding behaviour and that in this way the degree of sperm competition and ultimately male reproductive success is influenced.

Keywords Macaca fascicularis · Copulation calls · Sexual signal $\cdot$ Female reproductive status $\cdot$ Male dominance status · Ejaculation · Consortships · Estrogens ·

Progestogens $\cdot$ Faecal hormones

\section{Introduction}

In many animal taxa, sexual selection has led to the development of sexual signals, which either serve mate attraction (e.g. birds: Grant and Grant 1987; Hill 1991; Saetre et al. 1995; frogs: Gerhardt 1991), intrasexual competition for mates (e.g. primates: Kitchen et al. 2005) or both (e.g. lions: West and Packer 2002). In the vast majority of species, sexual signals are mainly exhibited by males as a result of male-male reproductive competition. In a few species, however, females have evolved conspicuous sexual signals, either due to a sex role reversal (pipefish, Syngnathus typhle, Berglund et al. 1997; Berglund and Rosenqvist 2001) or because males exhibit mate choice 
(crested auklets, Aethia cristatella, Jones and Hunter 1993, 1999; barn owls, Tyto alba, Roulin et al. 2000, 2001; bluefooted boobies, Sula nebouxii, Torres and Velando 2005).

Primates are unusual in that in many species, females have also developed sexual signals, such as swelling and colouration of sexual skin (for an overview, see Dixson 1983; SillénTullberg and Møller 1993; see also Setchell et al. 2006; Dubuc et al. 2009; Higham et al. 2010) as well as oestrus and copulation calls (e.g. Aujard et al. 1998; Moos-Heilen and Sossinka 1990; for a review on copulation calls, see Pradhan et al. 2006), even in species with no sex role reversal. The adaptive function of these female sexual signals remains largely unclear. Two of the more recently posed hypotheses that have attracted most attention are the "alpha-male notification" hypothesis (Henzi 1996), originally devised to explain female copulation calls, and the "graded-signal" hypothesis (Nunn 1999) developed to explain the occurrence of exaggerated sexual swellings (see Nikitopoulos et al. 2004; Maestripieri and Roney 2005; Zinner et al. 2004 for reviews). Both hypotheses postulate that female sexual signals provide males with information on female cycle stage as a way to motivate the group's alpha male to copulate with and mate guard her when conception is most likely to occur. Females may benefit from this by maximizing the chances that their offspring will be sired by the most dominant (and thus presumably a high-quality) male. Whereas the alpha-male notification hypothesis assumes that the signal's indication of the likelihood of conception is precise, the graded-signal hypothesis proposes that the signal indicates the probability of conception with a certain margin of imprecision taking into account that in many primate species, females may need to confuse paternity in order to reduce the risk of infanticide. There is now increasing evidence that female sexual swellings vary in size according to changes in female sex hormone levels and serve as a graded signal of the female fertile phase but that precision of the signal varies between species (bonobos, Pan paniscus: Reichert et al. 2002; chimpanzees, Pan troglodytes: Deschner et al. 2003; long-tailed macaques, Macaca fascicularis: Engelhardt et al. 2005; white-handed gibbons, Hylobates lar: Barelli et al. 2007; Barbary macaques, Macaca sylvanus: Brauch et al. 2007; yellow baboons, Papio cynocephalus: Gesquiere et al. 2007). Whether copulation calls (i.e. vocalisations during copulation) also vary in structure in accordance with female sex hormone levels and thus potentially function to indicate female reproductive status is, however, largely unknown.

Copulation calls mainly occur in Old World monkeys and apes and are generally confined to species with a multi-malemulti-female social organization (Dixson 1998; van Schaik et al. 1999). They most often occur together with female sex skin swellings. To date, there is only little (and mainly indirect) evidence in support of the assumption that the acoustic structure or frequency of the calls is related to female ovarian cycle stage. For example, call length in chacma baboons (Papio ursinus) peaks during the period of maximum swelling (the period around ovulation), suggesting that copulation calls may signal female cycle stage (O'Connell and Cowlishaw 1994) and in a study on Barbary macaques (M. sylvanus), Semple and McComb (2000) found that calls given early in the female ovarian cycle differ in acoustic structure to those given around midcycle. However, two subsequent more detailed studies in the Barbary macaques showed that neither the frequency (Brauch et al. 2007) nor the structure (Pfefferle et al. 2008a) of the calls reliably indicates the timing of the fertile phase.

In the absence of convincing evidence that copulation calls signal the female fertile phase, it has recently been proposed that these calls do not necessarily contain any information other than that the female has mated (Pradhan et al. 2006). By announcing that the female has been mating, female copulation calls should serve a dual function. If the call encourages male listeners to subsequently mate with the calling female, females benefit from increased sperm competition (originally suggested by O'Connell and Cowlishaw 1994). Alternatively, they benefit by biasing paternity and paternity certainty towards high-ranking males (originally suggested by Maestripieri and Roney 2005) if these prevent the female from subsequent mating with other males by mate guarding her. However, the fact that female copulation calls have a complex structure and can vary with respect to the mating male's age, social status and/or to the occurrence or absence of ejaculation (chacma baboons: O'Connell and Cowlishaw 1994; longtailed macaques: Deputte and Goustard 1980; yellow baboons: Semple 2001; Barbary macaques: Pfefferle et al. 2008a) contradicts the assumption that copulation calls only indicate that the female has been mating (see also Hamilton and Arrowood 1978). More acoustic analyses of copulation calls with endocrine assessment of female reproductive status are needed to improve our understanding of the information content and thus the function of female copulation calls in primates.

The long-tailed macaque represents a species in which sexually active females utter copulation calls in about $80 \%$ of all copulations (van Noordwijk 1985). Females usually start calling when the male stops thrusting and will continue to call even after the male has dismounted. Male long-tailed macaques are able to assess the female fertile phase (Engelhardt et al. 2004), and there is some indication that proportion of copulations accompanied by a call vary during the course of the ovarian cycle (Deputte and Goustard 1980), although we have recently shown that frequency of call occurrence does not indicate the timing of the fertile phase (Engelhardt et al. 2005). Whether the acoustic structure of calls is related to female cycle stage was not investigated. 
The overall aim of the present study was to analyse the structure of female copulation calls during the ovarian cycle and, by doing so, examine whether specific call parameters signal the probability of conception in wild long-tailed macaques. Firstly, we compared selected call parameters with female oestrogen to progestogen levels in order to identify the relationship between call structure and female hormonal status. Secondly, since it is known that other factors, such as the occurrence or absence of ejaculation and male identity, may also affect the structure of female copulation calls in primates (see above), these were also integrated into our analysis. We thus conducted a general linear mixed model in order to test the influence of female oestrogen and progestogen levels, the occurrence of ejaculation, male dominance status and whether a female was in consort with the mating male or not, on call parameter values.

\section{Methods}

Animals and study site

The study was carried out from April to July 2001 in the Recreation Park and Nature Reserve of Pangandaran, west Java, Indonesia $\left(7^{\circ} 43^{\prime} \mathrm{S}, 108^{\circ} 52^{\prime} \mathrm{E}\right)$. This area consists of mixed primary and secondary evergreen rain forest and has been described in detail by Kool (1993). Long-tailed macaques show a moderate degree of seasonality in reproduction with the birth season lasting for about 6 months (Kavanagh and Laursen 1984; van Schaik and van Noordwijk 1985) and birth peaks occurring in the study area around January and February (Engelhardt and Kusay 2002). The study females (CA, JA, AEB, WC, NF) belonged to four different groups and were all multiparous (for female rank and composition of the study groups, see Table 1). They had been monitored for at least a month before the recordings of copulation calls started and were those adult females which we clearly knew were cycling.
The study groups spent most of their time in the recreation park where visitors fed them occasionally. All animals of the study groups were habituated to observers and individually known.

The study was conducted completely non-invasively and under the permission of the authorities of Indonesia. We adhered to the Guidelines of the Use of Animals in Research, the legal requirements of Indonesia and the guidelines of the involved institutes.

Behavioural observations and recording of female copulation calls

All females of a group were monitored for sexual activity, consortships with males, sex skin swelling size, menstruation, pregnancy signs and infant birth or loss whenever in contact with the group, starting at least 1 month prior to the onset of the study. Observations and call recordings were carried out over the course of one ovarian cycle in each female using sex skin swelling as indication of ovarian activity. Hormone analysis later confirmed that all five study females were cycling and ovulating during the period of data collection. Females were followed every second day, and behavioural data were recorded using the focal animal sampling method (Altmann 1974). Observation time averaged $6.6 \mathrm{~h}$ per observation day. Consortships were continuously recorded using focal animal sampling (Altmann 1974). Consortships were defined as taking place when an adult male maintained proximity to the study female or the study female to an adult male within $5 \mathrm{~m}$ by coordinating his/her position and movements to the position and movements of the other for at least ten consecutive minutes. Sexual interactions (inspections, mating attempts, copulations) were recorded for all group members using the all occurrence method (Altmann 1974). Ejaculations were determined by the ejaculatory pause, which is common to many primates (Dixson 1998). During sexual interactions, the identity of the male and whether a female called during

Table 1 Study groups, number of adult males and females per group, identity, dominance rank and reproductive status of the five study females, observation time, number of calls and copulations analysed per female

\begin{tabular}{|c|c|c|c|c|c|c|c|c|}
\hline \multirow[t]{2}{*}{ Group } & \multicolumn{2}{|l|}{ Adult } & \multirow[t]{2}{*}{ Study female } & \multirow[t]{2}{*}{ Rank } & \multirow[t]{2}{*}{ Cycle type } & \multirow{2}{*}{$\begin{array}{l}\text { Observation } \\
\text { time (min) }\end{array}$} & \multirow[t]{2}{*}{ No. of calls } & \multirow{2}{*}{$\begin{array}{l}\text { No. of } \\
\text { copulations }\end{array}$} \\
\hline & Males & Females & & & & & & \\
\hline \multirow[t]{2}{*}{ A } & 5 & 7 & $\mathrm{CA}$ & 4 & $\begin{array}{l}\text { Conception cycle after death } \\
\text { of } 3 \text {-month-old infant }\end{array}$ & 4,889 & 31 & 198 \\
\hline & & & JA & 5 & $\begin{array}{l}\text { Non-conception cycle after } \\
\text { previous cycle }\end{array}$ & 2,704 & 16 & 74 \\
\hline B & 7 & 5 & AEB & 1 & $\begin{array}{l}\text { Non-conception cycle after } \\
\text { previous cycle }\end{array}$ & 4,537 & 32 & 159 \\
\hline $\mathrm{C}$ & 8 & 9 & WC & 4 & Conception cycle after previous cycle & 3,478 & 19 & 41 \\
\hline $\mathrm{F}$ & 4 & 12 & $\mathrm{NF}$ & 10 & $\begin{array}{l}\text { Conception cycle after death } \\
\text { of } 2 \text {-month-old infant }\end{array}$ & 5,679 & 30 & 213 \\
\hline
\end{tabular}


copulation was noted. In order to determine male and female rank, the sender and receiver of the 'bared-teethface', a unidirectional submissive display (van Hooff 1967), was recorded ad libitum when occurring between adult group members and entered a sociometric matrix (Altmann 1974).

Copulation calls were recorded ad libitum (distance 1-3 m) during focal animal sampling periods using a Sennheiser ME 66 directional microphone with a Sennheiser MZW 66 windshield and a SONY TCD-D 100 Digital Audio Tape Recorder. Only vocalisations given during copulations with adult males were recorded.

\section{Acoustic analysis}

Copulation calls of female long-tailed macaques consist of a sequence of distinct calls that can be divided into two main parts (Fig. 1): a sound produced during exhalation (exhales) and an only sometimes audible sound produced during inhalation (inhales). Both parts entered the analysis separately. All call sequences were sampled at a frequency of 44,100 Hz using Avisoft SAS Lab Pro 4.3 (Avisoft Bioacoustics, Berlin, Germany). In total, we recorded 278 copulation calls. Of these, we selected only those for analysis that were qualitatively suitable and given during either the prefertile, fertile or postfertile phase of the female ovarian cycle (as determined post hoc from faecal hormone analysis; see below). These 128 call sequences then underwent a 256-point fast Fourier transformation (FFT; filter bandwidth $350 \mathrm{~Hz}$, time resolution $1.5 \mathrm{~ms}$, frequency resolution $172 \mathrm{~Hz}$ ) and were analysed in a spectrogram with a Hamming window. The following structural/temporal call parameters were measured: call sequence duration, number of inhales per sequence, number of exhales per sequence, number of inhales per exhales, mean inhale duration, mean exhale duration, exhale rate (numbers per second) and mean exhale interval (see Table 2 for correlations between structural/temporal parameters).

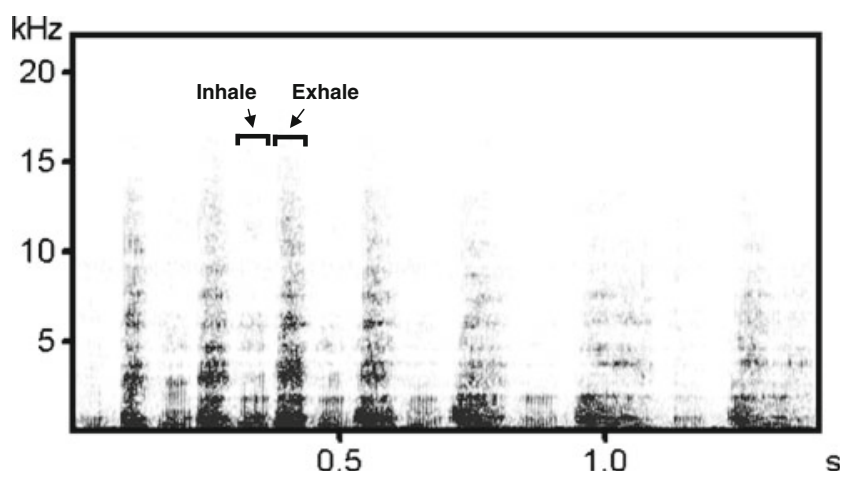

Fig. 1 Female copulation call. Inhales and exhales can easily be visually distinguished
To measure spectral call characteristics, calls were sampled down to $22,050 \mathrm{~Hz}$ to obtain a better frequency resolution. Up to three exhales and inhales were randomly selected from the middle part of each call sequence, and mean values per call sequence later on entered statistical analysis. For spectral analysis, the selected exhales and inhales underwent a 1,024-point FFT (filter bandwith $28 \mathrm{~Hz}$, time resolution $1.5 \mathrm{~ms}$, frequency resolution $22 \mathrm{~Hz}$, Hamming window) and resulting frequency time spectra were submitted to LMA 8.4 (Hammerschmidt 1990), which extracts sets of acoustic parameters from acoustic signals. In inhales, we obtained the fundamental frequency with the harmonic cursor function of SAS Lab Pro. In exhales, we measured the median peak frequency $(\mathrm{PF})$, which is the frequency at which the highest amplitude in a given time segment is reached ('dominant frequency' in Semple and McComb 2000), the dominant frequency band (DFB), which is characterized by amplitudes that exceed a given threshold in a consecutive numbers of time segments, and parameters that describe the amplitude distribution in the frequency spectrum, i.e. the frequency at which this distribution reached its first, second and third quartile of the total amplitude in each time segment (every $1.45 \mathrm{~ms}$ ), respectively (DFA1, DFA2 and DFA3). The algorithms are described in Schrader and Hammerschmidt (1997), and an illustration of the parameters can be found in Pfefferle et al. (2007, see Table 3 for correlations between spectral parameters).

Faecal sample collection, hormone analysis and definition of the cycle stages

Assessment of female cycle stage and timing of the fertile phase was based on oestrogen and progestogen measurements in regularly collected faecal samples as previously described in detail by Engelhardt et al. (2004). Briefly, 2-3 g of faeces was collected from each study female and stored in $15 \mathrm{ml}$ absolute ethanol at $4^{\circ} \mathrm{C}$ until transport to the endocrine laboratory. Steroids were extracted according to procedures described in Engelhardt et al. (2004), and extracts were measured for concentrations of immunoreactive total oestrogen (iEtotal) and pregnanediol glucuronide (iPdG), both having been shown to provide reliable information on female ovarian function and timing of ovulation in long-tailed macaques (Shideler et al. 1993; Engelhardt et al. 2004, 2007). Intra-assay coefficients of variation of quality controls were $7.2 \%(N=32)$ for iEtotal and $3.5 \%(N=32)$ for iPdG. Corresponding figures for inter-assay variation were $9.9 \%(N=16)$ and $5.5 \%(N=16)$ for iEtotal and iPdG, respectively (Engelhardt et al. 2004).

As described in Engelhardt et al. (2004), a defined rise in iPdG level above a threshold of the mean plus two standard deviations of three to five preceding baseline values was 
Table 2 Relationship between structural/temporal call parameters (Pearson's correlation coefficient)

\begin{tabular}{|c|c|c|c|c|c|c|c|c|c|}
\hline Parameter & $N=5$ & $\begin{array}{l}\text { Call } \\
\text { duration }\end{array}$ & $\begin{array}{l}\text { No. of } \\
\text { inhales }\end{array}$ & $\begin{array}{l}\text { No. of } \\
\text { exhales }\end{array}$ & Inhales/exhales & $\begin{array}{l}\text { Inhale } \\
\text { duration }\end{array}$ & $\begin{array}{l}\text { Exhale } \\
\text { duration }\end{array}$ & Exhales/s & $\begin{array}{l}\text { Exhale } \\
\text { interval }\end{array}$ \\
\hline \multirow[t]{2}{*}{ Sequence duration } & $r$ & & -0.327 & -0.492 & -0.075 & 0.830 & 0.624 & -0.807 & 0.688 \\
\hline & $P$ & & 0.591 & 0.400 & 0.904 & 0.082 & 0.260 & 0.099 & 0.199 \\
\hline \multirow[t]{2}{*}{ Number of inhales } & $r$ & -0.327 & & 0.664 & 0.880 & -0.358 & -0.094 & 0.644 & -0.495 \\
\hline & $P$ & 0.591 & & 0.222 & 0.049 & 0.554 & 0.880 & 0.241 & 0.396 \\
\hline \multirow[t]{2}{*}{ Number of exhales } & $r$ & -0.492 & 0.664 & & 0.233 & -0.818 & -0.770 & 0.909 & -0.924 \\
\hline & $P$ & 0.400 & 0.222 & & 0.707 & 0.091 & 0.128 & 0.033 & 0.025 \\
\hline \multirow[t]{2}{*}{ Inhales/exhales } & $r$ & -0.075 & 0.880 & 0.233 & & 0.065 & 0.370 & 0.245 & -0.058 \\
\hline & $P$ & 0.904 & 0.049 & 0.707 & & 0.917 & 0.540 & 0.691 & 0.926 \\
\hline \multirow[t]{2}{*}{ Inhale duration } & $r$ & 0.830 & -0.358 & -0.818 & 0.065 & & 0.928 & -0.935 & 0.964 \\
\hline & $P$ & 0.082 & 0.554 & 0.091 & 0.917 & & 0.023 & 0.020 & 0.008 \\
\hline \multirow[t]{2}{*}{ Exhale duration } & $r$ & 0.624 & -0.094 & -0.770 & 0.370 & 0.928 & & -0.788 & 0.904 \\
\hline & $P$ & 0.260 & 0.880 & 0.128 & 0.540 & 0.023 & & 0.113 & 0.035 \\
\hline \multirow[t]{2}{*}{ Exhales/s } & $r$ & -0.807 & 0.644 & 0.909 & 0.245 & -0.935 & -0.788 & & -0.945 \\
\hline & $P$ & 0.099 & 0.241 & 0.033 & 0.691 & 0.020 & 0.113 & & 0.015 \\
\hline \multirow[t]{2}{*}{ Exhale interval } & $r$ & 0.688 & -0.495 & -0.924 & -0.058 & 0.964 & 0.904 & -0.945 & \\
\hline & $P$ & 0.199 & 0.396 & 0.025 & 0.926 & 0.008 & 0.035 & 0.015 & \\
\hline
\end{tabular}

Values in italics depict statistically significant results

used to determine the presumed time of ovulation and to define the fertile phase (Fig. 2). On the basis of a time lag of 1-2 days in the excretion of progesterone metabolites into the faeces (Shideler et al. 1993) and given that samples were usually collected every second day, we determined a 3-day window in which ovulation was most likely. Specifically, we considered the second, third and fourth day before the defined faecal iPdG rise to represent the most likely days of ovulation (Engelhardt et al. 2004). The fertile phase of each ovarian cycle was then conservatively defined as the period comprising the 3 days of the ovulation window plus two preceding days since mating in long-tailed macaques can be fertile when occurring up to 2 days before and on the day of ovulation (Behboodi et al. 1991). Accordingly, the 6 days preceding the fertile phase was defined as the prefertile phase while the 6 days following the fertile phase were considered to represent the postfertile phase.

\section{Data analysis}

Since previous studies have shown that the oestrogen to progestogen $(\mathrm{E}: \mathrm{P})$ ratio is the best predictor for changes in

Table 3 Relationship between spectral call parameters (Pearson's correlation coefficient)

\begin{tabular}{|c|c|c|c|c|c|c|c|}
\hline Parameter & $N=5$ & $\begin{array}{l}\text { Fundamental } \\
\text { frequency }\end{array}$ & Peak frequency & DFB & DFA1 & DFA2 & DFA3 \\
\hline \multirow[t]{2}{*}{ Fundamental frequency } & $r$ & & -0.736 & 0.124 & 0.267 & 0.548 & 0.544 \\
\hline & $P$ & & 0.156 & 0.842 & 0.664 & 0.339 & 0.730 \\
\hline \multirow[t]{2}{*}{ Peak frequency } & $r$ & -0.736 & & -0.062 & -0.010 & 0.345 & 0.213 \\
\hline & $P$ & 0.156 & & 0.922 & 0.988 & 0.569 & 0.343 \\
\hline \multirow[t]{2}{*}{ DFB } & $r$ & 0.124 & -0.062 & & 0.709 & 0.719 & 0.765 \\
\hline & $P$ & 0.842 & 0.922 & & 0.180 & 0.171 & 0.132 \\
\hline \multirow[t]{2}{*}{ DFA1 } & $r$ & 0.267 & -0.010 & 0.709 & & 0.935 & 0.930 \\
\hline & $P$ & 0.664 & 0.988 & 0.180 & & 0.020 & 0.022 \\
\hline \multirow[t]{2}{*}{ DFA2 } & $r$ & 0.548 & -0.345 & 0.719 & 0.935 & & 0.973 \\
\hline & $P$ & 0.339 & 0.569 & 0.171 & 0.020 & & 0.005 \\
\hline \multirow[t]{2}{*}{ DFA3 } & $r$ & 0.544 & -0.213 & 0.765 & 0.930 & 0.973 & \\
\hline & $P$ & 0.343 & 0.730 & 0.132 & 0.022 & 0.005 & \\
\hline
\end{tabular}

Values in italics depict significant and statistically significant results 


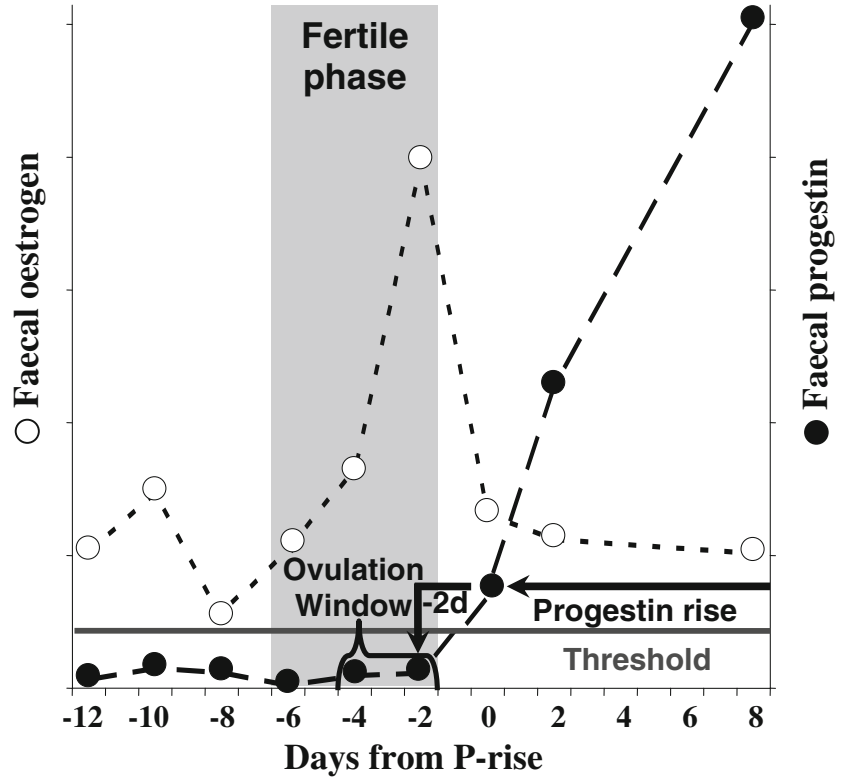

Fig. 2 Faecal oestrogen and progestin profile in an individual female long-tailed macaque (CA). The fertile phase was defined to be days -2 to -5 from the day of the rise in progestin levels (day 0 ) above a certain threshold (for more details, see "Methods" section)

sexual behaviour in female macaques (Zehr et al. 1998; Engelhardt et al. 2005) and is closely linked to female cycle stage being highest during the fertile phase (Engelhardt et al. 2005), mean E:P ratio values rather than values of the individual hormones were used for comparison of endocrine and call parameter patterns. In order to investigate temporal changes of frequency of call occurrence (calling rate) and call parameters and the E:P ratio values during the cycle, we calculated a mean value for each parameter per female per day. Subsequently, mean E:P ratios, mean calling rate and mean call parameter values were calculated across all five females for a given day, with E:P ratios being shifted backwards for 2 days to account for the time lag between hormone presence in blood and hormone excretion in faeces (see above). Days were then aligned to the last day of the fertile phase (day 0), and call parameters of days -12 up to 6 relative to the last day of the fertile phase were tested for a relationship with the mean E:P ratio using the Pearson's rank correlation coefficient.

We used general linear mixed models (GLMM) to analyse the effect of cycle stage, dominance status of the mating male, occurrence or absence of mate guarding by the mating male and occurrence or absence of ejaculation on the call parameters. A GLMM is an extension of the general linear model which accounts for unequal sample sizes and for repeated observations of the same subjects by including subject (female identity) as a random factor in the model (Pinheiro and Bates 1996). In addition to female ID as random factor, cycle stage, male dominance class, occurrence/absence of mate guarding and occurrence/ absence of ejaculation entered the model as fixed factors. We grouped males according to their ordinal rank, with males of ranks $1-3$ being classified as high ranking and all males ranking below being classified as low ranking. We tested data of call parameters for normal distribution using the Kolmogorov-Smirnov test. Data that were not normally distributed were $\log 2$ transformed before entering analysis. Since two of the observed females came from the same group, we ran the GLMM a second time adding group as co-random factor to female ID. Results did not change, but in some models, group was identified as being redundant. Furthermore, in two models, the Hessian matrix was not positive definite anymore when including group as random factor. We therefore show here data from models with female ID as random factor only.

In order to test whether dominance rank of the calling male had an influence on whether a female called or not, we calculated per male the percentage of copulations that occurred with a call. We then correlated these values with male ordinal rank using the Spearman's rank correlation coefficient.

To test whether females called more often when the male ejaculated than when he did not or when being mate guarded by the mating partner or not, we calculated per female the percentage of copulations with and without ejaculation during which she called and the percentage of copulations inside and outside mate guarding during which a female called, respectively. Individual mean values were then compared with each other using the exact Wilcoxon signed-ranks test (see Mundry and Fischer 1998). All statistical tests were two-tailed and carried out using SPSS 15.0.

\section{Results}

Copulation behaviour

Altogether, we recorded 685 copulations. Females called on average during $91.1 \%$ of all copulations (range 71.4 98.4\%). During $84.4 \%$ of copulations, females mated with high-ranking males (range $73.2-98.1 \%$ ) and $51.7 \%$ of copulations occurred with the group's dominant male (range $35.9-71.1 \%$ ). Males ejaculated in $89.4 \%$ of copulations (range $74.1-100 \%$ ).

Call parameters and E:P ratio and cycle stage

The E:P ratio showed a clear temporal pattern (Fig. 3a; for individual hormone profiles, see Engelhardt et al. 2004), 
Fig. 3 Pattern of the E:P ratio (a) and the selected call parameters, i.e. call duration (b), number of inhales (c), number of exhales (d), inhales per exhales ratio (e), inhale duration (f), exhale duration (g), number of exhales per second (h), exhale interval (i), fundamental frequency of inhales $(\mathbf{j})$, exhale peak frequency $(\mathbf{k})$, exhale DFB (l) and DFA1-3 of exhales (mo) for all five females (median, first and third quartile) during the course of the ovarian cycle. The shaded area indicates the fertile phase
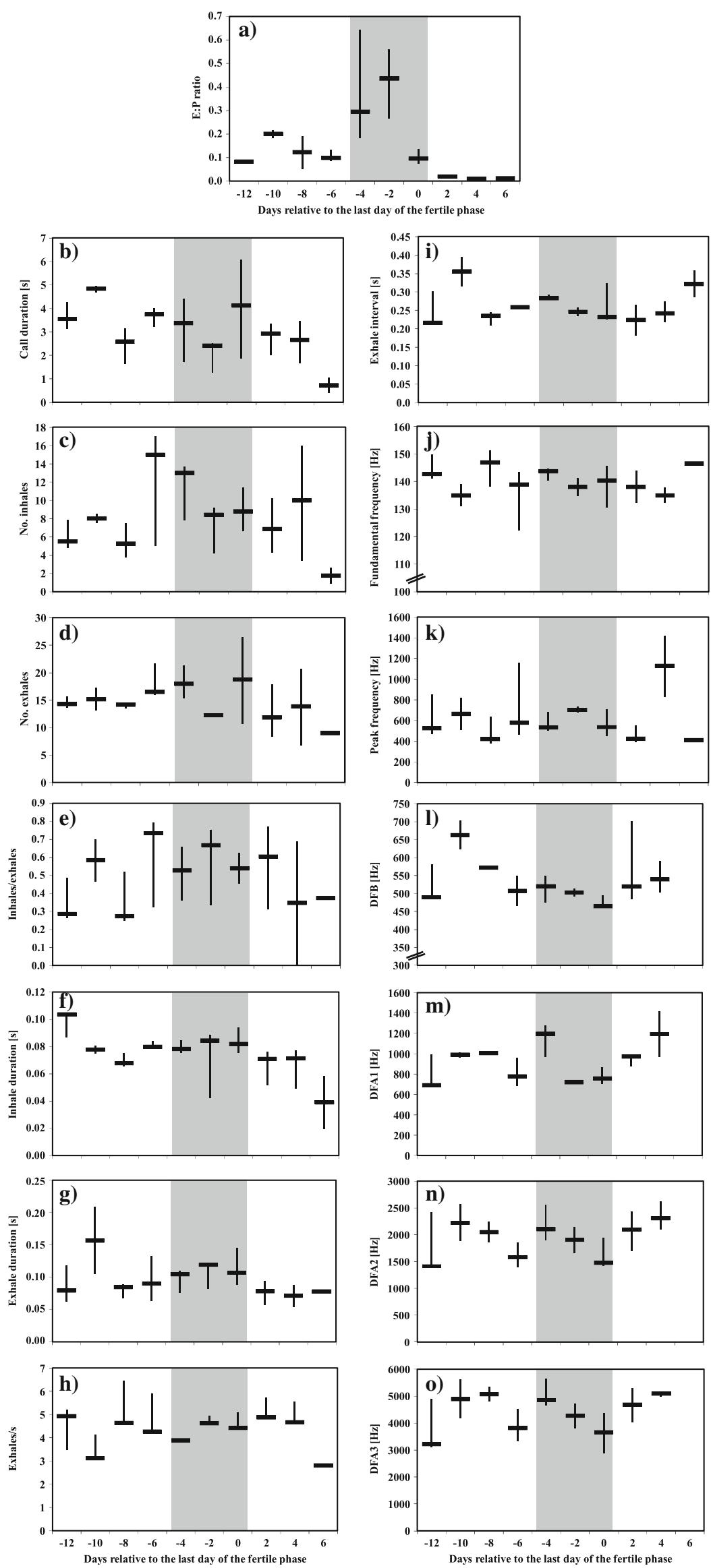
with a gradual increase in values from day -12 to reach a peak at day -2 relative to the last day of the fertile phase (day 0). Levels decreased markedly in the 6 days thereafter. In contrast to the E:P ratio, neither the frequency of call occurrence (calling rate) nor any of the tested copulation call parameters showed a clear change over the cycle (Fig. $3 b-g$ ), and there was no significant correlation between any of these parameters and the E:P ratio (calling rate: $r=0.323, N=10, P=0.363$; call duration: $r=0.176$, $N=10, P=0.626$; no. of inhales: $r=0.316, N=10, P=0.374$; no. of exhales: $r=0.153, N=10, P=0.674$; inhales/exhales: $r=0.436, N=10, P=0.208$; inhale duration: $r=0.349, N=10$, $P=0.323$; exhale duration: $r=0.618, N=10, P=0.057$; exhales/s: $r=-0.173, N=10, P=0.633$; exhale interval: $r=0.171, N=10, P=0.637$; fundamental frequency: $r=-0.098, N=10, P=0.788 ;$ PF: $r=0.047, N=10$, $P=0.897$; DFB: $r=0.051, N=9, P=0.896$; DFA1: $r=-0.134, N=9, P=0.732$; DFA2: $r=-0.086, N=9$, $P=0.825$; DFA3: $r=0.064, N=9, P=0.871)$. In accordance with this, none of the models revealed any significant effect of cycle stage on the structure of female copulation calls (Table 4).

\section{Call parameters and male rank and mate guarding}

Dominance status of the mating male had an effect on the number of copulations accompanied by a call. Although females called during almost each copulation, calling rate correlated significantly with rank of the mating partner, with females calling more often the lower-ranking their partner $\left(r_{s}=0.51, N=18, P=0.031\right.$; Fig. 4a). Variation in calling rate within ordinal ranks was however high. Dominance status of the mating male also explained part of the variation in call structure (Table 4, Fig. 5a). When females mated with high-ranking males, calls contained significantly more inhales per exhales $\left(\mathrm{F}_{1}, 101.2=5.017, P=0.027\right)$ compared with those uttered when females mated with subordinate males. On average, when mating with highranking males, females uttered calls with 15 exhales (range $11-21$ exhales) of which $63 \%$ (range $20-67 \%$ ) were accompanied by an inhale. In contrast, when mating with subordinate males, female calls consisted on average of 21 exhales (range 13-22 exhales) of which only 34\% (range 25-50\%) were accompanied by an inhale.

The temporal structure of calls was also affected by mate guarding (Table 4, Fig. 5b). When females copulated with a male by which they were mate guarded, exhales were significantly longer than when copulation took place outside the context of mate guarding $\left(\mathrm{F}_{1,},{ }_{101.1}=7.5\right.$, $P=0.008$ ). Apart from this, there was no significant effect of mate guarding on any of the other call parameters and also not on calling rate $\left(T^{+}=-4.05, N=5, P=0.813\right.$; Table 4).
Call parameters and ejaculation

In addition to male status, the occurrence of copulation calls and their structure were affected by occurrence/ absence of ejaculation. Whereas females called on average during $99.6 \%$ (range $98.4-100 \%$ ) of ejaculatory copulations, they called only during $41.9 \%$ (range $16.7-66.7 \%$ ) of copulations in which ejaculation did not occur (Fig. 4b). Due to the limited number of females observed, this difference, however, was not significant $\left(T^{+}=-2.02, N=5, P=0.063\right)$. Furthermore, when females called, the call sequence lasted significantly longer but tended to contain fewer exhales leading to significantly fewer exhales per second when the male ejaculated than when no ejaculation occurred (call duration: $\mathrm{F}_{1}, 102.4=5.0, P=0.027$; Table 4, Fig. $5 \mathrm{c}$; number of exhales: $\mathrm{F}_{1,100.0}=3.9, P=0.051$; Table 4; exhale rate: $\mathrm{F}_{1}$, $99.9=4.4, P=0.038$; Table 4, Fig. 5d). During ejaculatory copulations, females called on average for $4.1 \mathrm{~s}$ (range 3.5$5.0 \mathrm{~s}$ ) with 4.4 exhales/s (range 2.8-6.4 exhales/s) in contrast to $1.9 \mathrm{~s}$ (range $1.8-2.7 \mathrm{~s}$ ) with 5.1 exhales/s (range: $4.5-5.6$ exhales/s) when no ejaculation occurred.

\section{Discussion}

In this study, we analysed temporal and spectral changes in the structure of female copulation calls in long-tailed macaques in relation to endocrinologically determined stages of the female ovarian cycle in order to investigate whether calls provide reliable information on female reproductive status. Our results show that the timing of the fertile phase is not encoded in either the temporal or in the spectral structure of calls. We found, however, that the social status of the mating male whether he ejaculated or not and whether he mate guarded the female or not influenced calling frequency and/or call structure. The data thus demonstrate that copulation calls in long-tailed macaques provide information on mating circumstances and outcome and identity of the mating partner but are not signalling the probability of female fertility.

In a recent analysis, we have found that the frequency of female copulation calling in long-tailed macaques does not indicate the female fertile phase (Engelhardt et al. 2005). Similarly, in the current study, we did not find any significant relationship between any of the analysed call parameters and female sex hormone levels or cycle stage. Collectively these data suggest that female long-tailed macaques do not indicate their fertility status through the characteristics of copulation calls and that modulations in calling rate and structure are independent of female sex hormone levels. Thus our present finding neither supports the alpha-male notification hypothesis (Henzi 1996) nor the graded-signal hypothesis (Nunn 1999) for copulation calls. 
Table 4 Results of the GLMM for the effect of cycle stage, male rank class, mate guarding and ejaculation on the selected acoustic call parameters

\begin{tabular}{|c|c|c|c|c|c|}
\hline Dependent variable & & Cycle stage & Male rank class & Mate guarding & Ejaculation \\
\hline & $d f$ numerator & 2 & 1 & 1 & 1 \\
\hline \multirow[t]{3}{*}{ Call duration } & $d f$ denominator & 75.5 & 104.0 & 103.5 & 102.4 \\
\hline & $F$ & 1.383 & 697 & 0.624 & 5.005 \\
\hline & $P$ & 0.257 & 0.415 & 0.431 & 0.027 \\
\hline \multirow[t]{3}{*}{ No. of inhales } & $d f$ denominator & 103.3 & 100.8 & 101.0 & 100.2 \\
\hline & $F$ & 1.881 & 1.773 & 0.001 & 2.236 \\
\hline & $P$ & 0.158 & 0.86 & 0.976 & 0.138 \\
\hline \multirow[t]{3}{*}{ No. of exhales } & $d f$ denominator & 103.7 & 101.5 & 101.9 & 100.0 \\
\hline & $F$ & 1.125 & 2.271 & 0.018 & 3.914 \\
\hline & $P$ & 0.329 & 0.135 & 0.892 & 0.051 \\
\hline \multirow[t]{3}{*}{ Inhales/exhales } & $d f$ denominator & 103.6 & 101.2 & 101.4 & 100.5 \\
\hline & $F$ & 2.136 & 5.017 & 1.638 & 1.503 \\
\hline & $P$ & 0.123 & 0.027 & 0.203 & 0.223 \\
\hline \multirow[t]{3}{*}{ Inhale duration } & $d f$ denominator & 85.8 & 82.7 & 83.2 & 81.9 \\
\hline & $F$ & 0.111 & 0.717 & 1.407 & 2.906 \\
\hline & $P$ & 0.895 & 0.399 & 0.239 & 0.092 \\
\hline \multirow[t]{3}{*}{ Exhale duration } & $d f$ denominator & 100.4 & 100.1 & 100.1 & 100.0 \\
\hline & $F$ & 2.173 & 0.679 & 7.445 & 0.376 \\
\hline & $P$ & 0.119 & 0.412 & 0.008 & 0.541 \\
\hline \multirow[t]{3}{*}{ Exhales/s } & $d f$ denominator & 102.1 & 100.3 & 100.4 & 99.9 \\
\hline & $F$ & 0.995 & 0.120 & 0.451 & 4.421 \\
\hline & $P$ & 0.373 & 0.729 & 0.503 & 0.038 \\
\hline \multirow[t]{3}{*}{ Exhale interval } & $d f$ denominator & 102.2 & 100.3 & 100.4 & 99.8 \\
\hline & $F$ & 0.866 & 0.392 & 0.886 & 1.277 \\
\hline & $P$ & 0.424 & 0.533 & 0.349 & 0.261 \\
\hline \multirow[t]{3}{*}{ Fundamental frequency } & $d f$ denominator & 59.7 & 67.4 & 67.7 & 65.3 \\
\hline & $F$ & 1.432 & 0.003 & 2.304 & 0.264 \\
\hline & $P$ & 0.247 & 0.954 & 0.134 & 0.609 \\
\hline \multirow[t]{3}{*}{ Peak frequency } & $d f$ denominator & 27.1 & 77.9 & 75.0 & 71.5 \\
\hline & $F$ & 0.083 & 0.036 & 1.464 & 0.558 \\
\hline & $P$ & 0.920 & 0.850 & 0.230 & 0.457 \\
\hline \multirow[t]{3}{*}{ DFB } & $d f$ denominator & 60.2 & 65.8 & 67.1 & 64.4 \\
\hline & $F$ & 2.293 & 0.030 & 2.696 & 0.021 \\
\hline & $P$ & 0.110 & 0.863 & 0.105 & 0.887 \\
\hline \multirow[t]{3}{*}{ DFA1 } & $d f$ denominator & 54.1 & 58.2 & 60.3 & 57.7 \\
\hline & $F$ & 0.876 & 1.260 & 0.001 & 0.800 \\
\hline & $P$ & 0.422 & 0.266 & 0.974 & 0.375 \\
\hline \multirow[t]{3}{*}{ DFA2 } & $d f$ denominator & 58.6 & 57.7 & 59.5 & 57.4 \\
\hline & $F$ & 1.802 & 0.794 & 0.266 & 0.728 \\
\hline & $P$ & 0.174 & 0.377 & 0.608 & 0.397 \\
\hline \multirow[t]{3}{*}{ DFA3 } & $d f$ denominator & 60.0 & 57.4 & 58.6 & 57.2 \\
\hline & $F$ & 20.93 & 0.316 & 0.462 & 1.366 \\
\hline & $P$ & 0.132 & 0.576 & 0.499 & 0.247 \\
\hline
\end{tabular}

Values in italics depict statistically significant results

Calls however clearly conveyed socially relevant information. Male social status as well as information about the occurrence of mate guarding and ejaculation were reflected in either or both the likelihood with which females called and in the temporal characteristics of the call. Females called more often when ejaculation occurred, and these 
Fig. 4 Proportion of copulations in which a female called in relation to male ordinal rank (a) and occurrence and absence of ejaculation (b) (median, first and third quartile). $* P=0.031$, $* * P=0.063$

Fig. 5 Differences in the inhales per exhales ratio between calls uttered during copulations with high- and lowranking males (a), the exhale duration between calls uttered when a female was and was not mate guarded (b), and the call duration (c) and the number of exhales per second (d) between calls uttered during copulation with and without ejaculation (median, first and third quartile). $* P=0.027$, ** $P=0.008$, $* * * P=0.027, * * * * P=0.038$
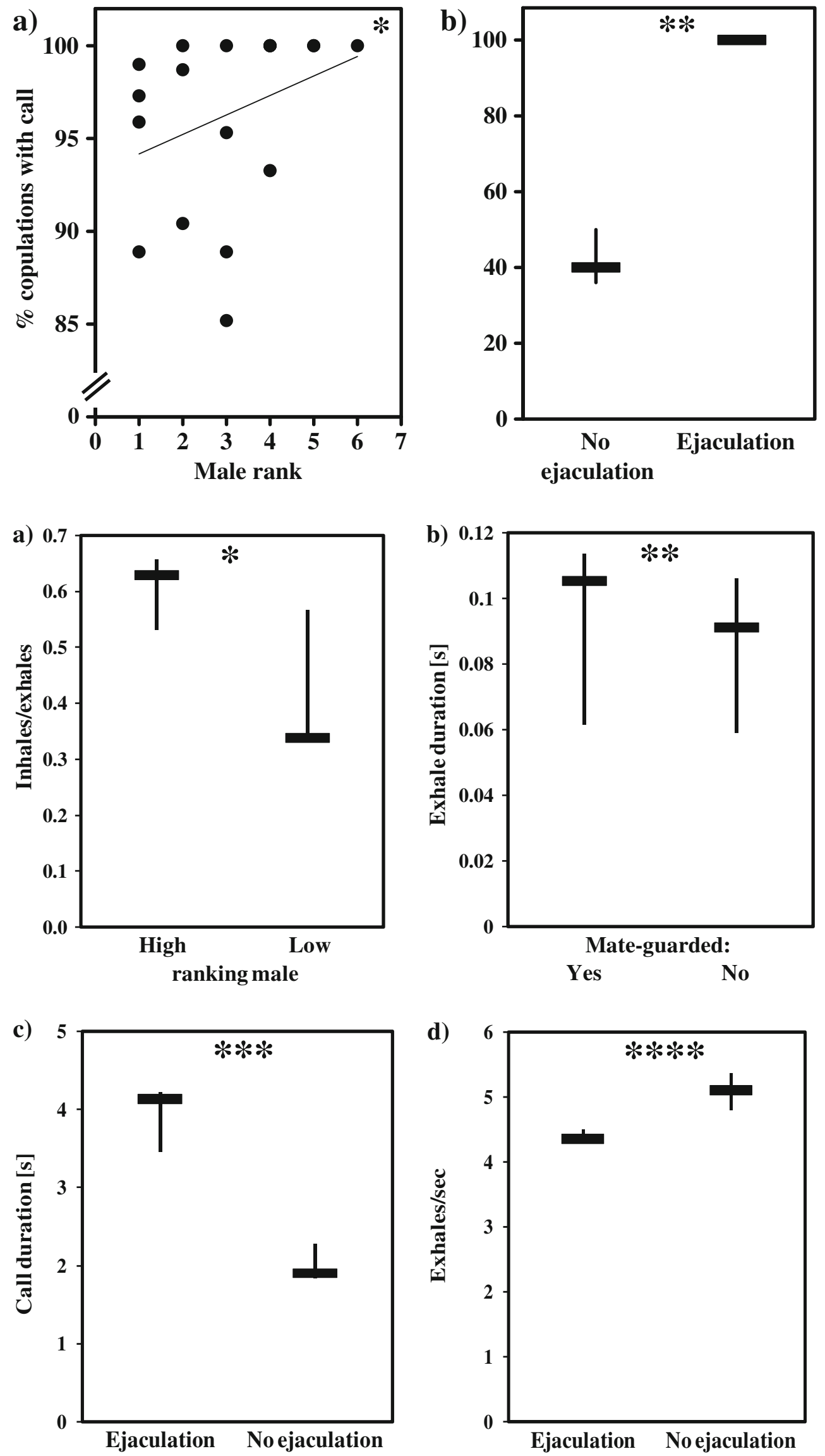
calls were longer than the calls given during copulations without ejaculation. Call duration was modified through exhale rate with females uttering more exhales per second when the male did not ejaculate. At the same time, females called less often when mating with high-ranking males, and these calls showed a higher inhale per exhale rate than those given during copulations with low-ranking males. When females were mate guarded, exhales were longer than during copulations outside of mate guarding. By uttering copulation calls and integrating information on ejaculation, mate-guarding status and rank of the mating partner into call structure, female long-tailed macaques may benefit in a dual way: firstly by increasing sperm competition and paternity confusion when signalling the occurrence of ejaculation and the absence of mate guarding thus attracting the attention of other males (Pfefferle et al. 2008b), particularly when receiving ejaculates from low-ranking males, and secondly by urging high-ranking males to mate guard calling females to prevent subsequent mating with other males and in this way biasing paternity and paternity certainty towards these (Maestripieri and Roney 2005). Even if the female would not be mate guarded by her mating partner, she may still bias paternity likelihood towards high-ranking males when indicating the high social status of her mating partner to others. Low-ranking males may be kept away from the female due to the risk of meeting a higher-ranking male with her (Semple et al. 2002), and thus sperm of high-ranking males may get an advantage in the competition for fertilising her ovum. Our interpretation is in line with results from previous studies showing that female long-tailed macaques prefer to mate polyandrously when not being mate guarded (Nikitopoulos et al. 2005; Engelhardt et al. 2006) and that paternity is highly biased towards dominant males (de Ruiter et al. 1994), even in the case of sperm competition (Engelhardt et al. 2006). Thus, information content of female copulation calls may have an important influence on the reproductive pattern found in this species.

Our results are the first to show that both social status of the mating partner and occurrence of ejaculation may be encoded in female primate copulation calls. So far, copulation calls either seemed to provide information on the occurrence of ejaculation (Barbary macaques, Pfefferle et al. 2008a) or on rank of the mating male (yellow baboons, Semple et al. 2002), but not both. In addition, we are the first to show that copulation calls may also convey information on whether a female is mate guarded or not. The reason for this variation in information content may be that female copulation calls serve different functions in different species depending on the degree with which male monopolisation of females occurs. Whereas in Barbary macaques females mate with multiple males and monopolisation of females plays a minor role (Brauch et al. 2008), male monopolisation prevails over mating with multiple males in yellow baboons (Alberts et al. 2006). The situation in long-tailed macaques is intermediated in that mating with multiple partners and mate guarding by the dominant male during the female fertile phase both occur to a significant extent (Engelhardt et al. 2006). This interpretation extends a recently developed model on the likelihood with which female primates should call when copulating (Pradhan et al. 2006). In this model, female primate copulation calls manipulate male reproductive behaviour in the way described above: high-ranking mating partners are urged into mate guarding, and listening males are attracted to mate with the female. The frequency with which females call during copulation is therefore predicted by the degree to which male monopolisation of females occurs. Our study in addition to those mentioned above however suggests that it is not only the frequency of call utterance that is affected by the degree of male monopolisation but also the social information conveyed in these calls. With the information available to males, their response (and thus male manipulation) can be expected to be more variable than suggested in the model since males should be able to assess the importance of mating with the female and the risk of approaching her. Male response to copulation calls should therefore vary in accordance with social status of the mating and listening male, with female mate-guarding status as well as with the occurrence or absence of ejaculation. A new model integrating these aspects is therefore needed in order to better understand the adaptive function of female copulation calls in primates.

Our findings are also relevant to our knowledge of functionally referential signalling. Signals found to convey specific information about objects or events external to the signaller have been collectively termed 'functionally referential' (Macedonia and Evans 1993). Two main diagnostic features of functionally referential signalling are production specificity and specificity in listeners' responses. According to our results, long-tailed macaque copulation calls fulfil the first criterion, namely production specificity. Further studies employing playback experiments are needed to confirm the second criterionthat the observed variation is actually meaningful to the subjects. In Barbary macaques, such playback experiments have revealed that male listeners are sensitive to variation in relation to copulation success (Pfefferle et al. 2008a). Moreover, although in Barbary macaques, as in long-tailed macaques, timing of the female fertile phase is not encoded in call structure (Pfefferle et al. 2008a), males are nevertheless able to distinguish between calls given during a very early stage of the cycle and during midcycle (Semple and McComb 2000; Pfefferle et al. 2008a). It is thus likely that the information encoded in female copulation calls is also salient to male long-tailed 
macaques, although playback experiments to test this assumption are still needed.

Our results are not in line with those of a previous study carried out on female copulation calls in captive long-tailed macaques (Nikitopoulos et al. 2004). In this study, calling rate did not differ with male rank and the occurrence or absence of ejaculation. However, the study by Nikitopoulos and colleagues was conducted on captive animals, i.e. mating females were constantly visible to other group members so that the audience may have affected female calling behaviour (Townsend et al. 2008). Furthermore, Nikitopoulos and colleagues did not distinguish between copulation calls uttered during the ovarian cycle and those uttered during pregnancy, although female sexual traits may differ between these two reproductive states in long-tailed macaques (Engelhardt et al. 2007).

Together, our findings that copulation calls of female longtailed macaques signal mating circumstances and outcome and rank of the mating partner suggest that these calls have a function in influencing mating patterns and thus play an important role in a reproductive context. We suspect that male mating and mate-guarding behaviour is manipulated by these calls and that in this way, the degree of sperm competition and ultimately male reproductive success is influenced. We further conclude that the variation in information content found in primate copulation calls of different species is related to differences in a female's general ability to manipulate male behaviour. How much influence females have over male behaviour in turn depends on the extent to which male monopolisation and polyandrous mating occurs in a given species (see also Pradhan et al. 2006). To verify this and thus shed further light on the function of copulation calls in female primates, more studies on the information content and use of female copulation calls in species with varying degrees of male monopolisation are required.

Acknowledgments We thank the Indonesian Institute of Sciences (LIPI) and the General Directorate of Forest Protection and Nature Conservation (PKA) for the co-operation and permission to conduct this study. We also wish to thank the Universitas Nasional (UNAS) for the scientific co-operation, Jutta Hagedorn and Andrea Heistermann for the laboratory assistance, Pak Kusay for the assistance in the field, Claudia Fichtel for the initial help with analysis, Roger Mundry for the advice on statistical analysis, Keith Hodges for the general improvement of the manuscript, and Tatiana Czeschlik, Joanna Setchell and two anonymous reviewers for the critical discussions on the manuscript. The German Academic Exchange Service (DAAD), the Lucie-Burgers Foundation for Comparative Research, Arnhem, the Netherlands and the State of Berlin Sponsorship for Female Young Scientists supported this study.

Open Access This article is distributed under the terms of the Creative Commons Attribution Noncommercial License which permits any noncommercial use, distribution, and reproduction in any medium, provided the original author(s) and source are credited.

\section{References}

Alberts SC, Buchan JC, Altmann J (2006) Sexual selection in wild baboons: from mating opportunities to paternity success. Anim Behav 72:1177-1196

Altmann J (1974) Observational study of behavior: sampling methods. Behaviour 49:227-267

Aujard F, Heistermann M, Thierry B, Hodges JK (1998) Functional significance of behavioral, morphological, and endocrine correlates across the ovarian cycle in semifree ranging female Tonkean macaques. Am J Primatol 46:285-309

Barelli C, Heistermann M, Boesch C, Reichard UH (2007) Sexual swellings in wild white-handed gibbon females (Hylobates lar) indicate the probability of ovulation. Horm Behav 51:221-230

Behboodi E, Katz DF, Samuels SJ, Tell L, Hendrickx AG, Lasley BL (1991) The use of a urinary estrone conjugates assay for detection of optimal mating time in the cynomolgus macaque (Macaca fascicularis). J Med Primatol 20:229-234

Berglund A, Rosenqvist G (2001) Male pipefish prefer ornamented females. Anim Behav 61:345-350

Berglund A, Rosenqvist G, Bernet P (1997) Ornamentation predicts reproductive success in female pipefish. Behav Ecol Sociobiol 40:145-150

Brauch K, Pfefferle D, Hodges K, Mohle U, Fischer J, Heistermann M (2007) Female sexual behavior and sexual swelling size as potential cues for males to discern the female fertile phase in free-ranging Barbary macaques (Macaca sylvanus) of Gibraltar. Horm Behav 52:375-383

Brauch K, Hodges JK, Engelhardt A, Fuhrmann K, Shaw E, Heistermann M (2008) Sex-specific reproductive behaviours and paternity in free-ranging Barbary macaques (Macaca sylvanus). Behav Ecol Sociobiol 62:1453-1466

de Ruiter JR, van Hoof JARAM, Scheffrahn W (1994) Social and genetic aspects of paternity in wild long-tailed macaques (Macaca fascicularis). Behaviour 129:203-224

Deputte BL, Goustard M (1980) Copulatory vocalizations of female macaques (Macaca fascicularis): variability factors analysis. Primates 21:83-99

Deschner T, Heistermann M, Hodges JK, Boesch C (2003) Timing and probability of ovulation in relation to sex skin swelling in wild West African chimpanzees, Pan troglodytes verus. Anim Behav 66:551-560

Dixson AF (1983) Observations on the evolution and behavioral significance of "sexual skin" in female primates. Adv Study Behav 13:63-106

Dixson AF (1998) Primate sexuality: comparative studies of the prosimians, monkeys, apes, and human beings. Oxford University Press, New York

Dubuc C, Brent L, Accamando A, Gerald M, MacLarnon A, Semple S, Heistermann M, Engelhardt A (2009) Sexual skin color contains information about the timing of the fertile phase in freeranging Macaca mulatta. Int J Primatol 30:777-789

Engelhardt A, Kusay (2002) Musim melahrikan kera ekor panjang (Macaca fascicularis) di Taman Wisata Alam dan Cagar Alam Pangandaran (Birth season of long-tailed macaques (Macaca fascicularis) in the Pangandaran Recreation Park and Nature Reserve). Surili 22:51-52

Engelhardt A, Pfeifer J-B, Heistermann M, Niemitz C, van Hooff JARAM, Hodges JK (2004) Assessment of female reproductive status by male longtailed macaques, Macaca fascicularis, under natural conditions. Anim Behav 67:915-924

Engelhardt A, Hodges JK, Niemitz C, Heistermann M (2005) Female sexual behavior, but not sex skin swelling, reliably indicates the timing of the fertile phase in wild long-tailed macaques (Macaca fascicularis). Horm Behav 47:195-204 
Engelhardt A, Heistermann M, Hodges JK, Nurnberg P, Niemitz C (2006) Determinants of male reproductive success in wild longtailed macaques (Macaca fascicularis): male monopolisation, female mate choice or post-copulatory mechanisms? Behav Ecol Sociobiol 59:740-752

Engelhardt A, Hodges JK, Heistermann M (2007) Post-conception mating in wild long-tailed macaques (Macaca fascicularis): characterization, endocrine correlates and functional significance. Horm Behav 51:3-10

Gerhardt HC (1991) Female mate choice in treefrogs: static and dynamic acoustic criteria. Anim Behav 42:615-635

Gesquiere LR, Wango EO, Alberts SC, Altmann J (2007) Mechanisms of sexual selection: sexual swellings and estrogen concentrations as fertility indicators and cues for male consort decisions in wild baboons. Horm Behav 51:114-125

Grant BR, Grant PR (1987) Mate choice in Darwin finches. Biol J Linn Soc 32:247-270

Hamilton WJ, Arrowood PC (1978) Copulatory vocalizations of chacma baboons (Papio ursinus), gibbons (Hylobates hoolock), and humans. Science 200:1405-1409

Hammerschmidt K (1990) Individuelle Lautmuster bei Berberaffen (Macaca sylvanus): Ein Ansatz zum Verständnis ihrer vokalen Kommunikation. PhD thesis, Free University Berlin

Henzi SP (1996) Copulation calls and paternity in chacma baboons. Anim Behav 51:233-234

Higham JP, Brent LJN, Dubuc C, Accamando AK, Engelhardt A, Gerald MS, Heistermann M, Stevens M (2010) Color signal information content and the eye of the beholder: a case study in the rhesus macaque. Behav Ecol 21:739-746

Hill GE (1991) Plumage coloration is a sexually selected indicator of male quality. Nature 350:337-339

Jones IL, Hunter FM (1993) Mutual sexual selection in monogamous seabird. Nature 362:238-239

Jones IL, Hunter FM (1999) Experimental evidence for mutual interand intrasexual selection favouring a crested auklet ornament. Anim Behav 57:521-528

Kavanagh M, Laursen E (1984) Breeding seasonality among longtailed macaques, Macaca fascicularis, in peninsular Malaysia. Int J Primatol 5:17-29

Kitchen DM, Cheney DL, Seyfarth RM (2005) Male chacma baboons (Papio hamadryas ursinus) discriminate loud call contests between rivals of different relative ranks. Anim Cogn 8:1-6

Kool KM (1993) The diet and feeding behavior of the silver leaf monkey (Trachypithecus auratus sondaicus) in Indonesia. Int J Primatol 14:667-700

Macedonia JM, Evans CS (1993) Variation among mammalian alarm call systems and the problem of meaning in animal signals. Ethology 93:177-197

Maestripieri D, Roney JR (2005) Primate copulation calls and postcopulatory female choice. Behav Ecol 16:106-113

Moos-Heilen R, Sossinka R (1990) The influence of oestrus on the vocalization of female gelada baboons (Theropithecus gelada). Ethology 84:35-46

Mundry R, Fischer J (1998) Use of statistical programs for nonparametric tests of small samples often leads to incorrect $P$ values: examples from Animal Behaviour. Anim Behav 56:256-259

Nikitopoulos E, Arnhem E, van Hooff JARAM, Sterck EHM (2004) Influence of female copulation calls on male sexual behavior in captive Macaca fascicularis. Int J Primatol 25:659-677

Nikitopoulos E, Heistermann M, de Vries H, van Hooff JARAM, Sterck EHM (2005) A pair choice test to identify female mating pattern relative to ovulation in longtailed macaques, Macaca fascicularis. Anim Behav 70:1283-1296

Nunn CL (1999) The evolution of exaggerated sexual swellings in primates and the graded-signal hypothesis. Anim Behav 58:229 246
O'Connell SM, Cowlishaw G (1994) Infanticide avoidance, sperm competition and mate choice: the function of copulation calls in female baboons. Anim Behav 48:687-694

Pfefferle D, West PM, Grinnell J, Packer C, Fischer J (2007) Do acoustic features of lion, Panthera leo, roars reflect sex and male condition? J Acoust Soc Am 121:3947-3953

Pfefferle D, Brauch K, Heistermann M, Hodges JK, Fischer J (2008a) Female Barbary macaque (Macaca sylvanus) copulation calls do not reveal the fertile phase but influence mating outcome. Proc R Soc Lond B Biol Sci 275:571-578

Pfefferle D, Heistermann M, Hodges JK, Fischer J (2008b) Male Barbary macaques eavesdrop on mating outcome: a playback study. Anim Behav 75:1885-1891

Pinheiro JC, Bates DM (1996) Unconstrained parametrizations for variance-covariance matrices. Statist Comput 6:289-296

Pradhan G, Engelhardt A, van Schaik C, Maestripieri D (2006) The evolution of female copulation calls in primates: a review and a new model. Behav Ecol Sociobiol 59:333-343

Reichert KE, Heistermann M, Hodges JK, Boesch C, Hohmann G (2002) What females tell males about their reproductive status: are morphological and behavioural cues reliable signals of ovulation in bonobos (Pan paniscus)? Ethology 108:583-600

Roulin A, Jungi TW, Pfister H, Dijkstra C (2000) Female barn owls (Tyto alba) advertise good genes. Proc R Soc Lond B Biol Sci 267:937-941

Roulin A, Riols C, Dijkstra C, Ducrest AL (2001) Female plumage spottiness signals parasite resistance in the barn owl (Tyto alba). Behav Ecol 12:103-110

Saetre GP, Fossnes T, Slagsvold T (1995) Food provisioning in the pied flycatcher: do females gain direct benefits from choosing bright-colored males. J Anim Ecol 64:21-30

Schrader L, Hammerschmidt K (1997) Computer-aided analysis of acoustic parameters in animal vocalizations: a multi-parametric approach. Bioacoustics 7:247-265

Semple S (1998) The function of Barbary macaque copulation calls. Proc R Soc Lond B Biol Sci 265:287-291

Semple S (2001) Individuality and male discrimination of female copulation calls in the yellow baboon. Anim Behav 61:10231028

Semple S, McComb K (2000) Perception of female reproductive state from vocal cues in a mammal species. Proc R Soc Lond B Biol Sci 267:707-712

Semple S, McComb K, Alberts S, Altmann J (2002) Information content of female copulation calls in yellow baboons. Am J Primatol 56:43-56

Setchell JM, Jean Wickings E, Knapp LA (2006) Signal content of red facial coloration in female mandrills (Mandrillus sphinx). Proc Roy Soc B 273:2395-2400

Shideler SE, Shackleton CHL, Moran FM, Stauffer P, Lohstroh PN, Lasley BL (1993) Enzyme immunoassays for ovarian steroid metabolites in the urine of Macaca fascicularis. J Med Primatol 22:301-312

Sillén-Tullberg B, Møller AP (1993) The relationship between concealed ovulation and mating systems in anthropoid primates: a phylogenetic analysis. Am Nat 141:1-25

Torres R, Velando A (2005) Male preference for female foot colour in the socially monogamous blue-footed booby, Sula nebouxii. Anim Behav 69:59-65

Townsend SW, Deschner T, Zuberbühler K (2008) Female chimpanzees use copulation calls flexibly to prevent social competition. PLoS One 3:e2431

van Hooff JARAM (1967) The facial displays of the catarrhine monkeys and apes. In: Morris D (ed) Primate ethology. Weidenfeld and Nicolson, London, pp 7-68

van Noordwijk MA (1985) Sexual behaviour of Sumatran longtailed macaques (Macaca fascicularis). Z Tierpsychol 70:277-296 
van Schaik CP, van Noordwijk MA (1985) Interannual variability in fruit abundance and the reproductive seasonality in Sumatran long-tailed macaques (Macaca fascicularis). J Zool 206:533-549

van Schaik CP, van Noordwijk MA, Nunn CL (1999) Sex and social evolution in primates. In: Lee PC (ed) Comparative primate socioecology. Cambridge University Press, Cambridge, pp 204-240

West PM, Packer C (2002) Sexual selection, temperature, and the lion's mane. Science 297:1339-1343
Zehr JL, Maestripieri D, Wallen K (1998) Estradiol increases female sexual initiation independent of male responsiveness in rhesus monkeys. Horm Behav 33:95-103

Zinner D, Nunn CL, van Schaik CP, Kappeler PM (2004) Sexual selection and exaggerated sexual swellings of female primates. In: Kappeler PM, van Schaik CP (eds) Sexual selection in primates: new and comparative perspectives. Cambridge University Press, Cambridge, pp 71-89 